\title{
Functionings and Capabilities as Tools for Explaining Differences in Self- Assessed Health: The Case of Women's Health in Accra, Ghana.
}

\author{
Nedialka Douptcheva' and Allan G. Hill ${ }^{2 *}$ \\ ${ }^{1}$ Harvard School of Public Health, Boston and Institut d'études démographiques et du \\ parcours de vie, Université de Genève, Genève. \\ ${ }^{2}$ Harvard School of Public Health, Boston and University of Southampton, UK. \\ ah4e10@soton.ac.uk
}

\begin{abstract}
We apply the Capability Approach on the data from a survey of women's health in Accra to illustrate how such a framework can capture health differentials. We identified endowment groups by based on the wealth of the households and the socio-economic status of the neighbourhood of residence and analysed their association with the functionings, measured by summary indicators of physical and mental health. Regression analysis reveals that socio-cultural and household factors do not have a significant association with health status. In turn, education appears to have the predicted association with both physical and mental health. Unemployed women suffer poorer health even when compared with women in informal jobs. Being childless is associated with better health, remembering that this is now a low fertility population. The two dimensions of health measured here - physical and mental - do have different determinants. The socio-economic status of the neighbourhood affects physical health while family wealth affects mental health more strongly.
\end{abstract}

Keywords: women's health, health differentials, capabilities, West Africa

\section{Résumé}

\section{Réalisations et Capabilités comme instruments pour expliquer les différences de santé auto-déclarée : le cas de la santé des femmes à Accra, Ghana.}

Nous appliquons l'approche des Capabilités aux données d'une enquête sur la santé des femmes à Accra pour illustrer comment ce cadre saisit les inégalités de santé. Nous avons défini des groupes de dotation en croisant la richesse du ménage et la situation socio-économique du quartier de résidence et analysé leurs liens avec les réalisations, mesurées par des indicateurs agrégés de santé physique et mentale. L'analyse de régression révèle que, en général, les facteurs socioculturels et du ménage ne sont pas associés significativement avec l'état de santé. En revanche, la scolarisation montre l'association attendue avec la santé tant physique que mentale. Les femmes au chômage ont une moins bonne santé, même en comparaison avec celles dans des emplois informels. Etre sans enfant apparaît associé à une meilleure santé, résultat à situer dans le contexte ghanéen actuel de faible fécondité. La santé physique et la santé mentale sont influencées différemment par les caractéristiques considérées. Le statut socio-économique du quartier affecte la santé physique tandis que la richesse de la famille affecte plus fortement la santé mentale.

Mots-clés: santé des femmes, inégalités de santé, Capabilités, Afrique de l'Ouest.

\section{* Corresponding author}




\section{Introduction}

There are several challenges with the adoption of a Capability Approach to the analysis of differentials in health in a population. Conceptually, the Capability Approach insists that no single indicator can successfully capture the dimensions of human well-being. In addition, the Capability Approach provides little help in the initial prioritisation of one indicator over another beyond the 10-point list of central capabilities proposed by Nussbaum (Nussbaum 20II)'. From first principles, we might assume that being able to survive a normal length of life and to remain in bodily health throughout that life assume greater importance than other concerns such as affiliation, concern for other species or control over one's environment. Practically, however, it seems almost impossible to discuss health-related functionings without collapsing some of the myriad indicators of health into summary indices. In the epidemiological model, the preferred analytic approach is to rank-order or weight causes and conditions and morbidity in terms of their lethality. Variations in this classification system allow for the combined use of mortality and morbidity for a range of diagnoses to construct widely used population-based measures built on the concept of disability adjusted life years, DALYs. Research in Ghana and elsewhere (Younis et al. 1993; Zurayk et al. 1995; Walraven et al. 200I), however, is pointing to the independence of measures of morbidity arrived at by questionnaires compared to measures derived from clinical examinations and biological tests.

A second large conceptual challenge revolves around the differences between Sen's approach that stresses the importance of the general concept of "freedom" and the more empirical approach proposed by Nussbaum that leads itself more naturally to the construction of indicators (Sen 1999). Nussbaum adopts a more juridical approach that links the concept of capabilities back to the rights-based movement. Sen, on the other hand, prefers to treat freedom as an overall good and to leave to each nation the task of selecting the specific capabilities its constitutional structure protects. In the latter case, priority-setting and the selection of one indicator over another becomes very difficult and open to the challenge that any choice of priorities is nation specific or culture-bound. In the health area, we are more accustomed to objective measures verifiable by multiple observers or multiple sources rather than accepting the judgement of a single assessor, whether that be a health professional or the individual concerned.

The third issue that complicates adoption of the Capability Approach for the analysis of health differentials and inequalities concerns the contribution of endowments to some final outcomes including health functionings. Whilst Sen, Nussbaum and others stress the importance of over-investment in those with disabilities, physical and mental, in order to raise their functioning to the levels enjoyed by the rest of the population, there are some features of people's initial characteristics which are difficult to manage, however large the investment. Think of cases of people who suffer from major genetic defects or even milder sickle cell traits which, even with current technology, are impossible to reverse or mitigate. These innate differentials seem to be of a different nature from other social or economic endowments which may be much more amenable to treatment as a result say, of education or job-training. Further, the socially and cultural defined nature of stigma adds an additional level of complexity in the assessment of functionings.

Finally, accounting for health differentials in terms of the hierarchy of measures ranging from endowments, functionings and capabilities raises some difficult issues. In the case of broad measures such as well-being or freedom, there are clearly many factors operating at different levels (individual, household, community, and nation) and no single well-accepted theory linking these outcomes with the causal factors. 
In explaining health differentials either at the individual or the community level, the case is quite different. There is a large body of science and empirical research that specifies, in quite detailed ways, the connections between certain diseases and conditions and causal elements, whether they be microbial or larger-scale affects such as exposure to common risks. The Capability Approach to health differentials therefore demands that we put aside some of the knowledge stemming from medical science and epidemiology which provides to the biomedical community a plausible explanation for many of the health differentials observed. This integration of the social and cultural assessment of health conditions takes us beyond the more narrowly familiar medical and epidemiological models.

Therefore, in this paper, using data from a recent study of women's health in Accra, we attempt to explore the links between perceived health and well-being using the components of the Capability framework in order to differentiate between the factors that influence our health and define our environment, our immediate surroundings, our personal traits, choices and preferences.

\section{Background}

Using the Capability Approach to assess the differentials in self-assessed health, we provide a framework that allows us to review the different trajectories that people take, given similar background social contexts (endowments) and the individual opportunities and choices (conversion factors) taken to arrive at different health states (functionings).

The data that we use for this exploration is from a household survey, conducted in 2008/9 among 2814 households in Accra, Ghana called the Women's Health Study of Accra, Wave II (WHSA-II) (Douptcheva and Hill 20II). The survey was intended to expand our understanding of the impact of health on poverty and development and to provide new empirical information on the epidemiology and demography of health and mortality in women and children in a major African city. The WHSA-II household questionnaire consisted of 25 sections in addition to a household roster and details of the dwelling's characteristics. The sections were chosen to address major health issues, as well as new topics of interest to policy makers and government programs. In this analysis we primarily focus on health and wellbeing as defined by the Medical Outcomes Study (MOS) short form (SF-36) - a series of 36 questions that measure functional health and well-being from as reported by the person interviewed. The instrument, although initially developed in high income settings, has been adapted and applied in a wide range of other settings including those similar to conditions in Accra (Hoopman et al. 2009; Wyss et al. 1999).

The construct of the SF-36 items, scales and summary measures occurs at three levels:

I. 36 items or questions in the questionnaire;

2. eight scales that aggregate between 2 10 items each; and

3. two summary component measures that aggregate the eight scales.

All of these 36 items with the exception of one (self-reported health transition item) are used in the computation processes (Ware and Gandek 1998a; Sullivan, Karlsson, and Ware 1995; Sullivan, Karlsson J Fau - Ware, and Ware; Ware and Gandek 1998b). Figure I explains the overall structure of the tool. 

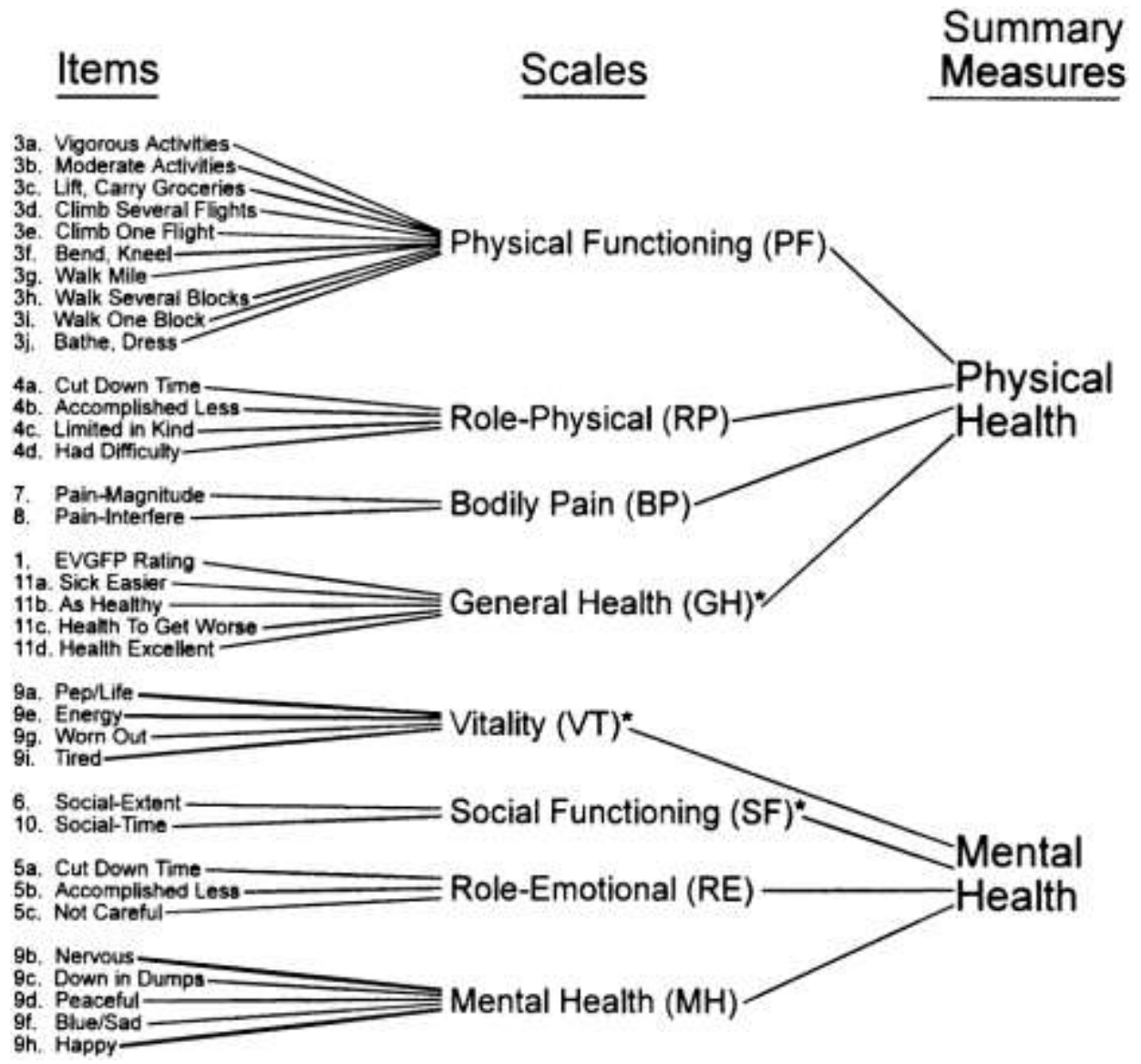

Source: Physical and Mental Summary Scales: A User Manual. Boston, MA: The Health Institutes

Figure I. The SF-36 measurement model.

Each item contributes to scoring only one scale. The SF-36 questions are used to construct composite measures of self-reported health and quality of life, emphasizing eight different domains of health - physical functioning, bodily pain, role limitations due to physical health, role limitations due to emotional problems, emotional well-being, energy/fatigue, social functioning, and general health perceptions. All eight scales or domains of health (see Figure I) are used to derive the two summary measures. The eight domains naturally fall into two different groups - general health and mental health. The two summary measures - Physical and Mental Health - are derived using principle components analysis applied to the unweighted scores. Structural validity was evaluated using factor analysis for the eight indexed scales of the SF-36 items by testing whether the observed data for the eight scales, collected during the study, correlated with the hypothetical structure of the two summary component scores, the physical component summary score (PCS) and the Mental component summary score (MCS). Two principal components emerged following rotation using the varimax method and tests validated the hypothesised two-dimensional structure underlying the eight SF-36 scales. For comparisons between the domains and between different populations, the raw scores are often standardized using population-based norms, producing norm-based scores related to the values in the reference population. Here we focus on the raw scores since we are not comparing the Accra women with women elsewhere in Africa or beyond. In general, 
higher scores, ranging from 0 to 100 , indicate better health.

\section{Capability Model}

An important first step in the analysis is the representation of key concepts in the Capability Approach in terms of the original variables available in the survey data. The wide variety of health measures makes it possible to consider differentials in health and the region determinants of health at different levels, and so to some extent the classification in every analysis is somewhat arbitrary. Nonetheless, Figure 2 shows the result of careful thinking and discussion about which measures of health will figure under the capabilities headings and which under the heading of functioning. The functionings shown on the right-hand side, both physical and mental, are derived from the factor analysis of the individual domain scores using the SF 36 instrument.

\begin{tabular}{|c|c|c|c|c|}
\hline Endowments & Conversion factors & Capabilities & $\begin{array}{l}\text { Selection/ } \\
\text { Preferences }\end{array}$ & Functionings \\
\hline $\begin{array}{l}\text { Context } \\
\text { - SES } \\
\text { Household } \\
\text { - Wealth }\end{array}$ & $\begin{array}{l}\text { Cultural/Social } \\
\text { - Ethnicity } \\
\text { - Region of birth } \\
\text { Household } \\
\text { - Head of household } \\
\text { Individual } \\
\text { - Age } \\
\text { - Education } \\
\text { - Marital status } \\
\text { - Occupation } \\
\text { - Pregnancies \& FP use } \\
\text { - Goes where if sick } \\
\text { - NHIS }\end{array}$ & $\begin{array}{l}\text { - Theoretical } \\
\text { range for } \\
\text { Physical health } \\
\text { - Theoretical } \\
\text { range for } \\
\text { Mental health }\end{array}$ & & $\begin{array}{l}\text { - Measured } \\
\text { physical health } \\
(\mathrm{PH}) \\
\text { - Measured } \\
\text { mental health } \\
(\mathrm{MH})\end{array}$ \\
\hline
\end{tabular}

Figure 2. Elements of the Capability Model used in this analysis.

\section{Endowments}

The endowments include the characteristic and resources of the surrounding environment and in our study are represented by neighbourhood socio-economic status (SES) and household wealth. SES is a variable based on the 2000 census and it describes the territorial division of the city, using neighbourhood, building and population characteristics as defined by the census for SES. Four SES groups describe the level of development, infrastructure and educational attainment, dividing the city into low class, low middle class, upper middle class and high class areas. The SES of the neighbourhood is thus a contextual endowment.
The construction of the wealth index included all household assets ${ }^{2}$ and utility services rather than a section of items. This broad criterion, with its greater number of indicator variables, improved the distribution of households with fewer households being allocated to certain index scores (Rutstein and Johnson 2004). All variables included in the index were dichotomized. The next step in the index construction used Principle Component Analysis (PCA) to calculate an index score. Using this method, the indicator variables were standardized (calculating z-scores); then the factor coefficient scores (factor loadings) were calculated; and finally, for each household, the indicator values were multiplied by the loadings and summed to produce the household's index value. In this process, only the first of the 
factors produced was used to represent the wealth index. The resulting sum is itself a standardized score with a mean of zero and a standard deviation of one (Rutstein and Johnson 2004). Some loss of precision is implied by the inclusion of binary or categorical variables in the PCA but the effects are critical for this application.

Using the index score, the wealth quintiles were created. The wealth index is used as a proxy for household wealth and it is considered a household endowment. The index is household possessions (durable goods). Using the distribution of the wealth score (-1.92 to 2.53) two equal size groups were created poorer and richer.

Using the contextual and household groups, using the working hypothesis that neighbourhood endowments can offset household or individual endowments, we create four endowment groups to determine the mix of resources available to the women in the survey (Figure 3).

\section{Wealth group I: poorer}

Wealth group 2: richer

\section{SES: low +
low middle class \\ SES: low +
low middle class}

Endowment group I: poorer in poorer areas

Endowment group 3: richer in poorer areas
SES: upper middle + high class

Endowment group 2: poorer in richer areas

Endowment group 4: richer in richer areas

constructed using housing characteristics and

Figure 3. Endowment groups used in this analysis.

\section{Conversion factors}

The conversion factors are all characteristics that are specific to a certain individual and they relate to personal, household, cultural/social choices and decisions made/achieved to reach the current state. The cultural/social, household and individual conversion factors available in the dataset are shown in Table I

Table I. Conversion factors by endowment group.

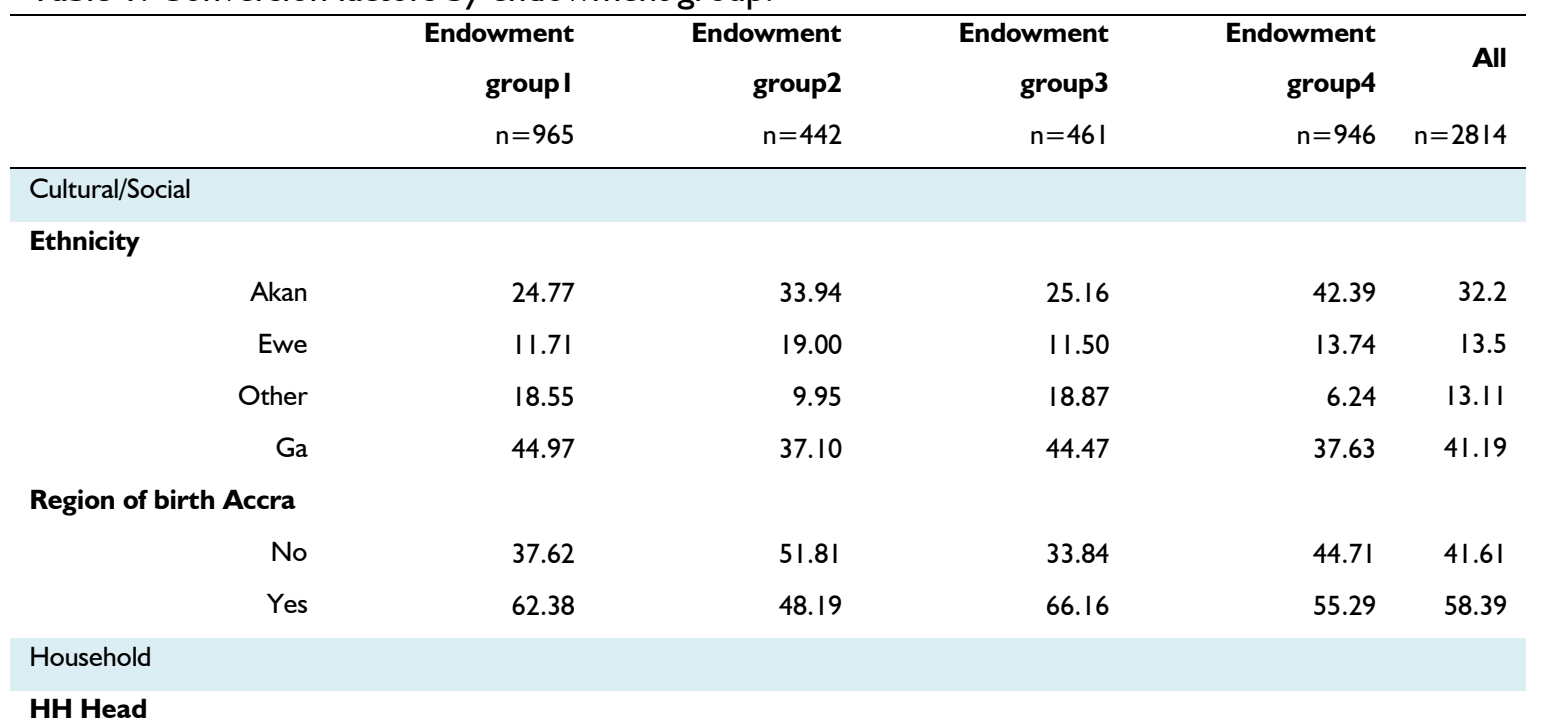




$\begin{array}{llllll}\text { No } & 58.96 & 56.11 & 68.33 & 65.96 & 62.40 \\ \text { Yes } & 41.04 & 43.89 & 31.67 & 34.04 & 37.60\end{array}$

Individual

Education

$\begin{array}{rr}\text { None } & 33.78 \\ \text { Primary } & 16.37 \\ \text { JSS } & 37.20 \\ \text { SSS + Higher } & 12.64\end{array}$

33.78

48.81

51.19

Not married

Goes where when sick

$$
\text { Nowhere }
$$

Medical

NHIS currently enrolled

$\begin{array}{ll}\text { Yes } & 27.49 \\ \text { No } & 72.51\end{array}$

7.88

16.48

75.65

27.49

27.67

20.52

25.60

26.22

$18-24$
$25-34$
$35-54$
$55+$

Occupation

$$
\begin{array}{r}
\text { formal } \\
\text { informal } \\
\text { unemployed able } \\
\text { unemployed unable }
\end{array}
$$

Number of pregnancies

$\begin{array}{rr}0 & 10.47 \\ 1-3 & 30.88 \\ 4-7 & 42.07 \\ 8+ & 16.58\end{array}$

4.46

63.52

13.89

18.13

9.50

12.22

78.28

31.00

69.00

26.24

24.43

27.83

21.49

4.09

67.27

|3.4 |

I 5.23

10.88

36.73

40.82

II.56
12. 15

13.23

41.87

32.75

55.75

44.25

7. 16

II.50

81.34

36.17

63.83

31.67

25.16

24.08

19.09

9.98

59.87

15.40

14.75

13.23

40.13

34.92

| I.7 |
17.76

13.44

12.37

21.93

7.51

12.33

$37.63 \quad 39.09$

$42.49 \quad 26.65$

$49.26 \quad 50.18$

$50.74 \quad 49.82$

$7.72 \quad 7.96$

$6.13 \quad|1.5|$

$86.15 \quad 80.53$

$43.01 \quad 34.60$

$56.99 \quad 65.20$

$26.96 \quad 27.86$

$20.40 \quad 21.86$

$24.95 \quad 25.48$

$27.70 \quad 24.80$

I4.74 8.76

$54.83 \quad 60.59$

$9.54 \quad 12.60$

$20.89 \quad 18.05$

$37.74 \quad 35.62$

$35.62 \quad 38.54$

$8.88 \quad|2.4|$
All variables have been recoded into groups that reflect the distribution of the data as well as the characteristics of the Ghanaian setting. All conversion variables are presented below with their relevant groupings. The following points are worth noting:

- The largest ethnic group represented in the sample is $\mathrm{Ga}(4 \mathrm{l} \%)$ followed by the Akan and the Ewe $(32.2 \%$ and $13.5 \%$ respectively). All other ethnic groups reported in the survey are grouped in the 'other' category, which represents $13.1 \%$ of the sample.

- 'Household head' indicates if the index woman has identified herself as a household head at the time of the interview. 
- The education variable represents completed level of education, divided into 4 groups - no education, primary, junior secondary school, senior secondary and higher.

- The 'married' category in marital status includes all women who identified themselves as married or living with a man (as if married); 'Not married' includes widowed, divorced, separated, never married.

- 'Goes where when sick' is a variable used for a proxy to determine use of health services, with the largest majority of women reporting that they go to a medical facility $(80.1 \%)$ which includes hospitals, clinics, health centres. Non-medical facilities include pharmacies, chemical shops, church, spiritualist, and selfmedication (I I.5\%).

- Information on enrolment in the National health insurance scheme (NHIS) shows that $35 \%$ of women reported that they were currently enrolled, while the remaining $65 \%$ report that they were not part of the scheme.

- Age group was determined by the sample selection.
- Occupation shows that the majority of the women in the survey $(60.6 \%)$ report that they have an informal occupation - street vendors, hawkers, food preparers, market traders; The women who have a formal waged or salaried occupation represent $8.8 \%$ of the sample; and those who are unemployed (both able and unable) represent $30.7 \%$ of the sample. Those who report they are unemployed and unable to work are most probably the older women in the sample.

- Number of pregnancies reflects what the interviewed woman reported when asked to list her pregnancy history and the categories are none $(13.4 \%), \quad I$ to 3 pregnancies $(35.6 \%), 4$ to 7 pregnancies $(38.5 \%)$ and more than 8 pregnancies (12.4\%).

\section{Capabilities}

The capabilities in the current model are expressed as the possible range of Physical and Mental health functioning shown in Table 2. The values have little intrinsic value since they are factor scores from the principal component analysis and therefore have only meaning in a relative sense.

Table 2. Capability set by endowment group

\begin{tabular}{|c|c|c|c|c|}
\hline & Endowment group I & Endowment group 2 & Endowment group 3 & Endowment group 4 \\
\hline & $\mathrm{n}=965$ & $n=442$ & $n=46 I$ & $\mathrm{n}=946$ \\
\hline \multicolumn{5}{|l|}{ PH_factor } \\
\hline mean & -0.111 & 0.046 & 0.047 & 0.068 \\
\hline Std Dev & 1.014 & 0.968 & 0.995 & 0.995 \\
\hline Variance & 1.028 & 0.938 & 0.990 & 0.989 \\
\hline Index of dispersion & 9.26 & 20.39 & 21.06 & 14.54 \\
\hline $\min$ & -3.534 & -3.296 & -3.096 & -3.319 \\
\hline $\max$ & 1.302 & 1.302 & 1.302 & 1.302 \\
\hline \multicolumn{5}{|l|}{ MH_factor } \\
\hline mean & -0.148 & -0.045 & 0.116 & 0.116 \\
\hline Std Dev & 1.052 & 0.943 & 0.983 & 0.958 \\
\hline Variance & 1.107 & 0.889 & 0.967 & 0.918 \\
\hline Index of dispersion & 7.48 & 19.75 & 8.34 & 7.91 \\
\hline $\min$ & -4.582 & -3.447 & -3.890 & -4.264 \\
\hline $\max$ & 1.536 & 1.536 & 1.536 & 1.536 \\
\hline
\end{tabular}




\section{Selection/Preferences}

There are no variables that measure selection/preferences in the WHSA-Il dataset. An additional qualitative study is being prepared to address that issue, particularly around the issue of obesity preferences for certain body sizes addressed in previous work (Duda et al. 2007). The results of this work will be incorporated into more detailed evaluations of the Capability Approach in Ghana.

\section{Functioning set}

For the purposes of the analysis and simplification of interpretation, a single Physical health measure was constructed using factor analysis on the variables pertaining to physical health - physical functioning, bodily pain, role limitation physical and general health. Similarly, a Mental health indicator was constructed using the mental health variables - role limitation emotional, emotional wellbeing, energy/fatigue and social functioning. The distributions of the two resulting variables - $\mathrm{PH}$ _factor (Physical health) and $\mathrm{MH}$ factor (Mental health) are right-skewed since most women were in good health.

\section{Results}

\section{Predictors/determinants of functioning}

The results in Table 3 indicate that, taking into consideration the whole sample, there are different factors that have an effect on Physical and Mental health. While SES and wealth are important for Mental health, they are not significant predictors for better Physical health. Reversely, age has an effect on Physical health but not on Mental health. Having no children has a positive effect on Mental health while having more than 4 children has a negative effect on Physical health. No education or some education, as well as unemployment, affect both Physical and Mental health negatively while not going anywhere when sick shows to be beneficial.

In order to explore further the conditions which determine the different outcomes in Physical and Mental health functionings, a stratified analysis is performed using the endowment groups to review if differences exist within those groups as well as between the groups. That analysis allows us to determine which are the factors that differentiate certain achievements/well-being given similar contextual and household background.

\section{Predictors/determinants of functioning within endowment groups}

The results of the linear regression exploring the relationship between conversion factors and functioning (physical and mental) stratified by endowment groups are also presented in Table 3.

Table 3. Predictors/determinants of functioning

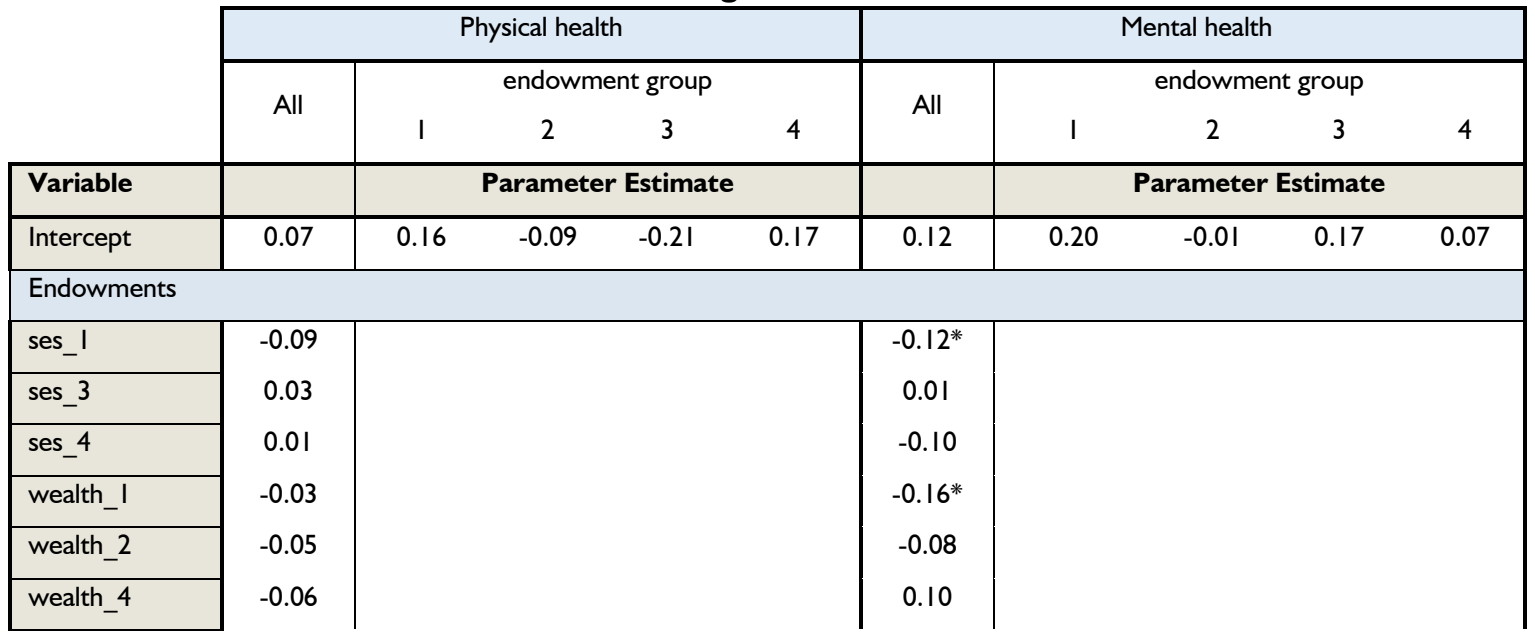




\begin{tabular}{|c|c|c|c|c|c|c|c|c|c|c|}
\hline wealth_5 & 0.04 & & & & & $0.12^{*}$ & & & & \\
\hline \multicolumn{11}{|l|}{ Cultural/Social } \\
\hline ethn I & 0.05 & 0.06 & -0.02 & 0.16 & 0.02 & 0.00 & -0.01 & -0.11 & -0.10 & 0.08 \\
\hline ethn2 & 0.02 & -0.03 & 0.00 & -0.06 & 0.09 & -0.06 & -0.02 & -0.03 & $-0.37^{*}$ & 0.04 \\
\hline ethn3 & 0.07 & 0.10 & -0.08 & -0.07 & 0.13 & 0.07 & 0.06 & 0.02 & 0.00 & 0.15 \\
\hline region_acc & -0.05 & 0.03 & -0.13 & -0.02 & -0.09 & -0.02 & 0.02 & -0.17 & -0.18 & 0.05 \\
\hline \multicolumn{11}{|l|}{ Household } \\
\hline HHhead & -0.01 & -0.05 & 0.10 & 0.13 & -0.09 & 0.04 & 0.03 & 0.15 & -0.04 & 0.01 \\
\hline \multicolumn{11}{|l|}{ Individual } \\
\hline edu0 & $-0.29 *$ & $-0.35^{*}$ & $-0.29 *$ & -0.14 & $-0.28 *$ & $-0.26^{*}$ & $-0.32 *$ & -0.21 & -0.14 & $-0.34 *$ \\
\hline edul & $-0.11 *$ & $-0.20 *$ & 0.06 & -0.01 & -0.14 & $-0.21^{*}$ & $-0.28 *$ & 0.07 & -0.23 & $-0.28 *$ \\
\hline edu3 & 0.05 & 0.12 & 0.08 & 0.05 & 0.02 & 0.01 & -0.01 & 0.14 & -0.01 & 0.01 \\
\hline $\mathrm{msl}$ & 0.05 & 0.04 & -0.01 & $0.20 *$ & 0.00 & 0.06 & 0.01 & 0.00 & 0.16 & 0.07 \\
\hline goes0 & $0.29 *$ & $0.33^{*}$ & $0.39 *$ & 0.25 & $0.26 *$ & $0.17 *$ & 0.13 & $0.45^{*}$ & 0.04 & 0.12 \\
\hline goes I & 0.08 & 0.11 & 0.12 & 0.02 & 0.05 & $0.29 *$ & $0.37^{*}$ & $0.33^{*}$ & 0.00 & $0.26 *$ \\
\hline NHIS & 0.06 & -0.05 & $0.18 *$ & -0.01 & $0.11 *$ & 0.03 & -0.06 & -0.05 & 0.09 & 0.06 \\
\hline agesvyl & $0.28 *$ & $0.25 *$ & 0.21 & $0.58^{*}$ & $0.21^{*}$ & 0.08 & -0.01 & 0.17 & 0.22 & 0.10 \\
\hline agesvy2 & $0.21^{*}$ & $0.20 *$ & 0.17 & $0.4 I^{*}$ & 0.12 & 0.01 & -0.02 & -0.05 & 0.12 & 0.01 \\
\hline agesvy4 & $-0.32 *$ & $-0.22 *$ & -0.25 & $-0.39 *$ & $-0.43^{*}$ & -0.06 & -0.04 & -0.23 & 0.25 & -0.15 \\
\hline occ_form & 0.03 & 0.00 & -0.05 & 0.03 & 0.04 & 0.07 & -0.01 & -0.14 & 0.07 & 0.14 \\
\hline occ_unempll & $-0.12 *$ & -0.06 & -0.11 & -0.09 & $-0.24 *$ & $-0.24^{*}$ & $-0.27^{*}$ & 0.03 & $-0.36 *$ & $-0.28 *$ \\
\hline occ_unempl2 & $-0.70^{*}$ & $-0.7 I^{*}$ & $-0.93 *$ & $-0.46^{*}$ & $-0.67^{*}$ & $-0.55^{*}$ & $-0.59 *$ & $-0.49 *$ & $-0.49 *$ & $-0.5 I^{*}$ \\
\hline pregn0 & 0.10 & 0.06 & $0.32 *$ & 0.01 & 0.09 & $0.19 *$ & $0.28^{*}$ & $0.46^{*}$ & 0.16 & 0.04 \\
\hline pregn47 & $-0.09 *$ & -0.10 & -0.04 & -0.10 & -0.04 & -0.03 & -0.11 & 0.17 & -0.16 & 0.01 \\
\hline pregn8 & $-0.15^{*}$ & -0.16 & -0.19 & -0.10 & -0.20 & -0.06 & -0.10 & 0.17 & -0.26 & -0.11 \\
\hline
\end{tabular}

* significant at 0.05 level

The following points are worth noting from the above analysis:

- Cultural/social and household conversion factors do not have significant effects on physical health.

- Cultural/social and household conversion factors do not have a significant effect on mental health, except for Ewe women from richer families living in poorer areas compared to $\mathrm{Ga}$ women in the same endowment group; Ewe women have a significantly smaller chance of scoring high on the $\mathrm{MH}$ score.

- Women with no education, compared to women with junior secondary school education have decreased chance of scoring higher on the physical health score.
- Poorer women living in poorer areas and richer women living in richer areas who have no or only primary education have significantly lower chance of scoring higher on the mental health score compared to women from those area with junior secondary school education.

- Married women from richer families in poorer areas have an increased chance of scoring higher on the $\mathrm{PH}$ score compared to women from the same areas who are not married.

- Women who do not go anywhere when sick compared to those who go to a medical facility have significantly higher chance of scoring higher on the physical health score

- Women who go to non-medical facilities when sick have significantly higher chance of scoring higher on the mental health score 
compared to those who go to medical facilities when sick.

- Age is an important predictor for physical health but not important for mental health

- The biggest positive effect of age on physical health is experienced by younger wealthier women living in poor areas, while the biggest negative effect affects the oldest age group of richer women living in richer areas. Mental health differentials follow a similar pattern.

- Unemployed unable women from all endowment groups have significantly lower chance of scoring higher on both the physical and mental health scale compared to women who have informal jobs

- Poorer women from richer neighbourhoods who have no children (pregnancies), compared to women with I-3 children from the same areas have significantly higher chance of scoring higher on both the Physical and Mental health scale.

\section{Predictors/determinants of functioning between endowment groups}

Through the analysis of variance and using the General Linear Model (GLM) procedure with a contrast option, we explore the differences in functioning (Physical and Mental) between the 4 endowment groups. The contrast analysis allows us to test the significance of predicted specific differences in particular parts of groups. Thus, contrasting each of the four endowment groups against each of the other 3 , we find whether there are any significant differences in the regression coefficients for Physical and Mental health between the groups, controlling for all the conversion factors. The results of the analysis are presented in Table 4.

Table 4. Comparing functioning between groups

\begin{tabular}{|c|c|c|c|c|c|c|c|c|c|}
\hline \multirow[b]{2}{*}{ Contrast } & \multirow[b]{2}{*}{ DF } & \multicolumn{4}{|c|}{ Physical health } & \multicolumn{4}{|c|}{ Mental health } \\
\hline & & $\begin{array}{r}\text { Contrast } \\
\text { SS }\end{array}$ & $\begin{array}{c}\text { Mean } \\
\text { Square }\end{array}$ & F Value & $\operatorname{Pr}>\mathbf{F}$ & $\begin{array}{r}\text { Contrast } \\
\text { SS }\end{array}$ & $\begin{array}{c}\text { Mean } \\
\text { Square }\end{array}$ & F Value & $\operatorname{Pr}>\mathbf{F}$ \\
\hline I $v 2$ & $I$ & 3.6408 & 3.6408 & 5.64 & $0.0176^{*}$ & I.3854 & I.3854 & 1.66 & 0.1978 \\
\hline I v 3 & I & 0.0435 & 0.0435 & 0.07 & 0.795 I & 6.7262 & 6.7262 & 8.06 & $0.0046 *$ \\
\hline I v 4 & I & 6.1563 & 6.1563 & 9.54 & $0.0020 *$ & 14.5817 & 14.5817 & 17.47 & $<.000 I^{*}$ \\
\hline 2 v 3 & I & 2.2033 & 2.2033 & 3.42 & 0.0647 & 1.4265 & 1.4265 & 1.71 & 0.1912 \\
\hline $2 v 4$ & I & 0.0521 & 0.0521 & 0.08 & 0.7763 & 4.4514 & 4.4514 & 5.33 & $0.0210 *$ \\
\hline $3 v 4$ & 1 & 3.8622 & 3.8622 & 5.99 & $0.0145^{*}$ & 0.5799 & 0.5799 & 0.69 & 0.4047 \\
\hline
\end{tabular}

* significant at 0.05 level

Looking at the endowment groups whose regression coefficients for Physical health and Mental health are significantly different $(I \vee 2$, I v 4, 3 v 4 for Physical health and I v 3, I v 4 and $2 \vee 4$ for Mental health) we establish that there are different patterns that determine those differences (Figure 4). Exploring the characteristics of the endowment groups (SES and wealth), we can determine that the directionality of the differences suggests that SES (or context endowment) is important determinant for Physical health, while wealth (or household endowment) is important for Mental health. 


\section{SES}

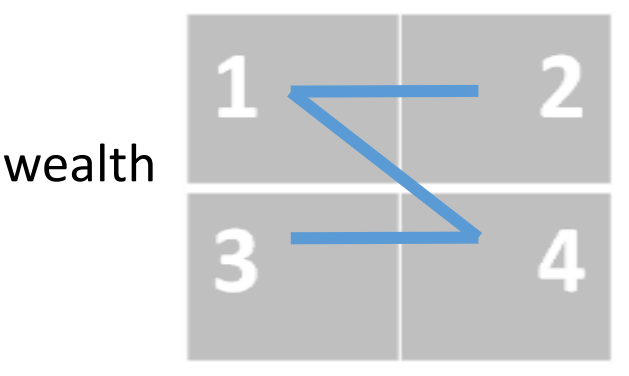

SES

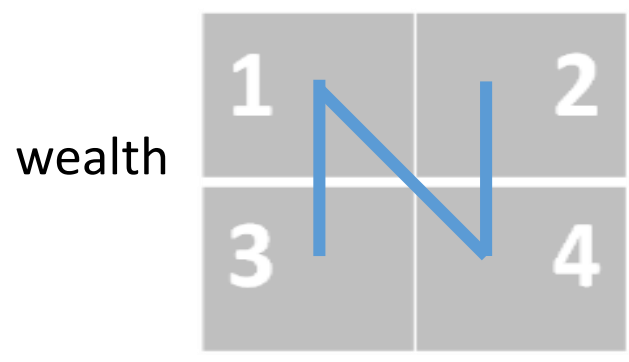

Figure 4. Directionality of significant differences between groups for Physical and Mental health

\section{Discussion}

Some of the important findings that result from the analysis include the differences in the predictors for functionings - Physical and Mental health. Looking at differences within groups, cultural/social and household conversion factors have almost no significant effect on Physical and Mental health. For individual conversion factors, age is a significant predictor for Physical health but does not have an effect on Mental health. The effect of no children in some of the endowment groups has a significant role for better Physical and Mental health, a feature perhaps peculiar to this low fertility population, while not surprisingly unemployment for women who are unable to work has very strong negative effect on both Physical and Mental health.

Considering the differences between endowment groups, it is important to point out the different factors that have an effect on Physical and Mental health, i.e. SES has an influence on Physical Health while wealth influences Mental Health.

Some of the limitations that restrict the breadth of this analysis relate to the use of secondary data. There were no variables identified as possible proxies for individual endowments in order to explore their relationship to the outcomes of interest or the interaction with other endowments or conversion factors. Similarly, no data on personal preferences/choices is available in the data set.

\section{Summary and conclusion}

In this paper we have used data from Women's Health Study of Accra, Wave II, to investigate the effects of endowments and conversion factors on functionings (Physical and Mental health), defined in terms of self-rated health and stratified by endowment characteristics. We have shown that there are different predictors and factors determining Physical and Mental health and they are expressed within and between endowment groups.

The analysis begs a number of questions about the definitions of endowments, conversion factors and functionings in the context of health. As Ariana and Naveed point out, there has been a dearth of discussion in the academic literature about what constitute health capabilities (Deneulin and Shahani 2009). They lay emphasis on the difference between achieved functionings which are readily measureable and broader notions of potential functionings. They are also ambivalent about the use of weights to distinguish "elementary functionings" (Sen) from more "complex functionings" (Sen) such as self-respect. 
Clearly, we are at the stage of experimenting with different approaches to employing the Capability Approach to understanding health differentials and inequities and approaches which complement the one above may be necessary.

\section{References}

Ariana, P., and A. Naveed, 2009. Health. Chapter 10 in S. Deneulin and L. Shahani, eds., An introduction to the human development and capability approach, Earthscan, London.

Deneulin, S., and L. Shahani. Eds, 2009. An introduction to the human development and capability approach: freedom and agency. London; Sterling, VA, Ottawa, ON: Earthscan;International Development Research Centre.

Douptcheva N, Hill AG, (20I I) Final Report on the Women's Health Study of Accra, Wave II. Accra, Technical Publication N. 91, Institute for Statistical, Social and Economic Research, University of Ghana.

Duda, R. B., N. A. Jumah, A. G. Hill, J. Seffah, and R. Biritwum. 2007. Assessment of the ideal body image of women in Accra, Ghana. Trop Doct 37 (4):24I-4.

Hoopman, R., C. B. Terwee, W. Deville, D. L. Knol, and N. K. Aaronson. 2009. Evaluation of the psychometric properties of the SF-36 health survey for use among Turkish and Moroccan ethnic minority populations in the Netherlands. Qual Life Res 18 (6):753-64.

Nussbaum, Martha C. (2000) Women and Human Development: The Capabilities Approach (Cambridge University Press, Cambridge).

Nussbaum, M. C. 20II. Creating capabilities: the human development approach. Cambridge, Mass.: Belknap Press of Harvard University Press.

Rutstein SO, Johnson K (2004) The DHS Wealth Index, DHS Comparative Reports No.6, ORC Macro Nussbaum's, Calverton, MD
Sen, A. 1999. Development as freedom. New York: Knopf.

Sullivan, M., J. E. Karlsson J Fau-Ware, Jr., and J. E. Ware, Jr. The Swedish SF-36 Health Survey--I. Evaluation of data quality, scaling assumptions, reliability and construct validity across general populations in Sweden. (0277-9536 (Print)).

Sullivan, M., J. Karlsson, and J. E. Ware, Jr. 1995.

The Swedish SF-36 health survey-I evaluation of data quality, scaling assumptions, reliability and construct validity across general populations. Social Science \& Medicine 4 I (I0): I349-I358.

Walraven, G., C. Scherf, B. West, G. Ekpo, K. Paine, R. Coleman, R. Bailey, and L. Morison. 200 I. The burden of reproductiveorgan disease in rural women in The Gambia, West Africa. Lancet 357 (9263): I I6I-7.

Ware, J. E., Jr., and B. Gandek. 1998a. Methods for testing data quality, scaling assumptions and reliability: the IQOLA Project Approach. Clinical Epidemiol 5 I (I I):945-952.

1998b. Overview of the SF-36 Health Survey and the International Quality of Life Assessment (IQOLA) Project. J Clin Epidemiol 5 I (I I):903-I2.

Wyss, K., A. K. Wagner, D. Whiting, D. M. Mtasiwa, M. Tanner, B. Gandek, and P. M. Kilima. 1999. Validation of the Kiswahili version of the SF-36 Health Survey in a representative sample of an urban population in Tanzania. Qual Life Res 8 (I2): I I I-20.

Younis, N., H. Khattab, H. Zurayk, M. elMouelhy, M. F. Amin, and A. M. Farag. 1993. A community study of gynecological and related morbidities in rural Egypt. Stud Fam Plann 24 (3): I 75-86.

Zurayk, H., H. Khattab, N. Younis, O. Kamal, and M. el-Helw. 1995. Comparing women's reports with medical diagnoses of reproductive morbidity conditions in rural Egypt. Stud Fam Plann 26 (I): |4-2I. 
${ }^{1}$ I0-point list of central capabilities includes: life; bodily health; bodily integrity; senses, imagination, and thought; emotions; practical reason; affiliation; engaging with other species; play; and control over one's environment. See Nussbaum (2000) for full details.

${ }^{2}$ Type of dwelling, main roofing, tenure, water supply, toilet, cooking fuel, kitchen, bathing, liquid waste, nets, sewing machine, mobile telephone, house phone, refrigerator, television, private car, washing machine, computer, radio, electronic iron. 